\title{
Muestras de madera colectadas en Córdoba en el siglo XVIII descubiertas en el Real Jardín Botánico de Madrid
}

\author{
Ángel Montero | Real Jardín Botánico de Córdoba \\ Url de la contribución <www.iaph.es/revistaph/index.php/revistaph/article/view/4935>
}

\section{RESUMEN}

Este trabajo se centra en los estudios sobre un personaje ilustrado y su correspondencia, así como en el estudio de otra documentación perteneciente al antiguo Real Gabinete de Historia Natural (siglo XVIII). El trabajo documental ha llevado a descubrir entre los fondos antiguos del Herbario del Real Jardín Botánico de Madrid muestras de maderas de Sierra Morena correspondientes a colectas del último tercio del siglo XVIII. Fueron realizadas por Fernando López de Cárdenas, cura párroco en Montoro (Córdoba, España). Estas colectas se hicieron a partir de la "instrucción de colecta" que se realizó desde la Corte a instancias del Real Gabinete en 1776, pero se desconocía que hubieran sobrevivido hasta nuestros días.

La colección encontrada en el Real Jardín Botánico de Madrid consta de setenta y cuatro ítems de maderas, mientras que la parte de la colección traspasada en 1844, con origen en Sierra Morena, constaba de setenta y nueve ejemplares. Los ejemplares, casi en su totalidad, conservan sobre la madera datos manuscritos por el propio López de Cárdenas (s. XVIII), así como las etiquetas del Real Gabinete (s. XVIII) y las del Real Jardín Botánico (s. XIX) pegadas en la superficie cortada.

Se han hecho listados de las especies enviadas al Real Gabinete en Madrid, así como de las especies allí existentes después de la invasión francesa, también de los ejemplares transferidos al Herbario MA del Real Jardín Botánico de Madrid y de los que existen actualmente en esta Institución.

\section{Palabras clave}

Archivos | Botánica | Córdoba | España | Historia | López de Cárdenas | Maderas | Real Gabinete de Historia Natural | Real Jardín Botánico | Siglo XVIII | 


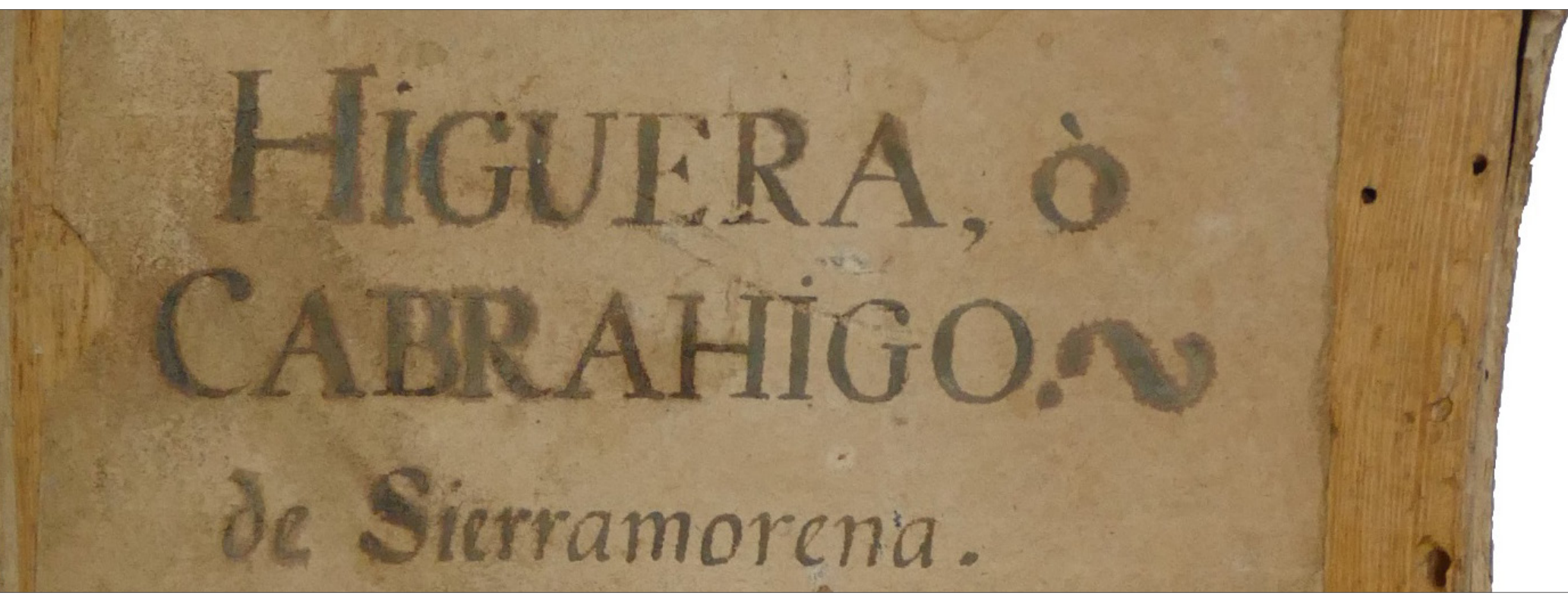

\section{Samples of woods collecting in Córdoba, in the 18th century, discovered in the Royal Botanical} Garden of Madrid

\section{ABSTRACT}

This work focuses on studies on an illustrated character and his correspondence, as well as on the study of other documentation belonging to the old Royal Cabinet of Natural History (18th century). This documentary work has led to the discovery among the ancient collections of the Herbarium of the Royal Botanical Garden of Madrid samples of wood from Sierra Morena corresponding to collections from the last third of the 18th century. They were carried out by Fernando López de Cárdenas, parish priest in Montoro (Córdoba, Spain). These collections were made from the "collection instruction" that was carried out from the Court at the request of the Royal Cabinet in 1776, but it was unknown that they had survived to this day. The collection found in the Royal Botanical Garden of Madrid consists of seventy-four items of wood, while the part of the collection transferred in 1844, originating in Sierra Morena, consisted of seventy-nine specimens. The specimens, almost in their entirety, preserve on the wood itself data handwritten by López de Cárdenas himself (18th century), as well as the labels of the Royal Cabinet (18th century) and that of the Royal Botanical Garden (19th century) glued on the cut surface. Lists have been made of the species sent to the Royal Cabinet in Madrid, as well as of the species existing there after the French invasion, also of the specimens transferred to the Herbarium MA of the Royal Botanical Garden of Madrid and of those that currently exist in this Institution.

\section{Keywords}

Archives | Botany | Córdoba | Spain | López de Cárdenas | Wood samples | Royal Cabinet of Natural History | Royal Botanical Garden |

Cómo citar: Montero, A. (2022) Muestras de madera colectadas en Córdoba en el siglo XVIII descubiertas en el Real Jardín Botánico de Madrid. Revista PH, n. ${ }^{\circ}$ 105, pp. 118-131. Disponible en: <www.iaph.es/revistaph/index.php/revistaph/article/view/4935> DOI 10.33349/2022.105.4935>

Enviado: 19/04/2021 | Aceptado: 21/12/2021 | Publicado: 10/02/2021 


\section{INTRODUCCIÓN}

En Madrid, el Real Jardín Botánico del Paseo del Prado, heredero de proyectos anteriores (Velayos, García y Velayos 2020), desarrolló y profundizó en el último cuarto del siglo XVIII el carácter docente de la Botánica. El estudio de esta materia ya había comenzado en los anteriores proyectos, adaptándose al impulso cultural y científico ilustrado y dando también los primeros pasos en la vertiente investigadora. Centralizaría y almacenaría los ejemplares que enviaban los colectores peninsulares, así como las colecciones que las expediciones botánicas recogían en las provincias de ultramar, llevando a cabo intentos de aclimatación de muchas de esas plantas (Añón 1987; Puerto Sarmiento 1988; López 2005; Armada 2005).

Así mismo, otra institución que nació con el impulso ilustrado, el Real Gabinete de Historia Natural, seguía la tradición de la nobleza europea de acumular y exponer unas colecciones de objetos naturales con una ordenación sistemática. Además, allí se iniciaron los estudios de las diferentes ramas de la Historia Natural, excepto la Botánica (Barreiro 1992, 1944; Hernández-Pacheco 1944; Calatayud Arinero 1988; Calatayud Arinero 1986; Montero, 2003)

Ambas instituciones, Jardín y Gabinete, iniciaron su andadura por separado y siguieron su actividad en paralelo. Por tanto, cada una tenía sus propios colectores y corresponsales y su plantilla propia de profesores y conservadores. Aunque ambas comenzaron su actividad separadas, a partir de 1815 las dos formarían parte de una suprainstitución el Real Museo de Ciencias Naturales, junto con el Laboratorio Químico y el Real Estudio de Mineralogía. En 1845 se integraron en la Facultad de Filosofía.

El Real Gabinete tuvo desde su inauguración una Sala de Botánica llamada Sala para el Reino Vegetal o Sala del Vegetal, pero todo el material botánico que se encontraba expuesto o almacenado en el Real Gabinete se traspasaría al Jardín Botánico en 1844 en una operación de cesión de colecciones entre instituciones. La imperiosa necesidad de espacio por la continua entrada de ejemplares de animales, rocas, minerales y fósiles y el poco interés por la botánica, que además ya desarrollaba el Jardín Botánico, haría que esta sala desapareciera antes de terminar la primera mitad del siglo XIX. En otro orden de cosas, hay que tener en cuenta que el ingreso de ejemplares al Real Gabinete era continuo desde su creación y una de las entradas era a través de la colecta. Con ese fin se emitieron instrucciones de colecta tanto desde el Real Gabinete, en 1776 (Lemoine Villicaña 1961), como desde el Real Jardín en 1779 (Gómez Ortega 1992).

La instrucción de colecta del gabinete del año 1776, en el apartado del Reino Vegetal, dice entre otras cosas: "De todos los Arboles que se encontraren 
en cualquiera parte se enviará: I. Un pedazo de madera con su corteza, sea del tronco ó de las ramas, que tenga media vara de largo, y seis pulgadas de diámetro, poco mas ó menos..." (sic). También se piden hojas secas, flores, frutos, resinas y toda la información que se posea del árbol en cuestión. El problema existente en todas las posesiones de la corona era la falta de personas con algún conocimiento científico para hacer frente a semejante encargo de recolecta. Lo específico del tema requería personas instruidas y preparadas para esa tarea, para primero reconocer y después colectar, preparar, embalar y enviar ejemplares de historia natural. Unos años antes de la compra por Carlos III de la colección de Franco Dávila para crear su Real Gabinete de Historia Natural, en una carta de este en la que insta al ministro Campomanes a convencer al rey para comprar su gabinete, ya le avisa que no es fácil ni barato hacer acopio de ejemplares de historia natural (MSS. Ref. 48-95. Archivo de Campomanes, en adelante AC).

A pesar de haberse emitido la ya citada ordenanza desde la Corte, en 1776, para promover las colectas, ordenanza que afectaba a virreyes, gobernadores, corregidores, alcaldes, etc., la escasez de colectores competentes fue habitual. Aun así, la entrada de ejemplares, en muchos casos inservibles, era continua. Como se ha dicho antes, esto fue debido, principalmente, a las pocas personas que había en el país con formación en esas materias, pero también hay que resaltar que el gabinete real no pagaba por lo enviado, ni siquiera sufragaba los gastos ocasionados por las colectas, y eso a pesar de la recomendación del Intendente de Córdoba para que se premiara a los colectores (MSS/2541. Biblioteca Digital Hispánica, en adelante BDH). Eran comunes las continuas peticiones de los colectores explicando lo costoso de la tarea o haciendo exposiciones, a veces largas, de la necesidad de un sueldo o alguna paga o de algún nombramiento remunerado para ellos o para algún familiar (Calatayud Arinero 1987, refs. 442, 634, 651, 714). Respecto a esto último, solo hubo una excepción en Andalucía y fue la de Fernando López de Cárdenas, que consistió en 50 doblones de oro y un título honorífico en 1779 , tres años después de empezar a enviar colecciones al Real Gabinete (Calatayud Arinero 1987, ref. 540).

\section{MATERIAL Y MÉTODOS}

Para conocer la actividad de los colectores y de los ejemplares enviados al Real Gabinete de Historia Natural en el siglo XVIII, se han utilizado documentos del Archivo del Museo Nacional de Ciencias Naturales-CSIC (AMNCN), así como las referencias a esos documentos del Catálogo de documentos

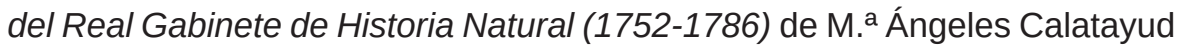
Arinero (1987). Esas referencias han sido usadas en este trabajo para citar los manuscritos manejados. También, del mismo Archivo, se ha utilizado el documento de inventario, fechado en 1819 , de todas las maderas que conte- 
nía el Real Gabinete y el Inventario de las maderas, resinas y frutos que de orden de la Junta Gubernativa del museo de ciencias naturales, su fecha 11 de junio de 1844 deben trasladarse al Jardín Botánico de esta Corte desde el Gabinete de Historia natural, donde en la actualidad se hallan. Se ha utilizado documentación del Archivo de Campomanes (AC), Fundación Universitaria Española, y se ha obtenido información de documentación incluida en la Biblioteca Digital Hispánica (BDH), Biblioteca Nacional de España.

Por último, se han estudiado y fotografiado los ejemplares de maderas cortadas que se encuentran actualmente en el Herbario MA del Real Jardín Botánico de Madrid con procedencia de Sierra Morena, con números de inventario de MA-01-00940644 a MA-01-00940700 y de MA-01-00948232 a MA-01-00948248.

\section{RESULTADOS}

En el último tercio del siglo XVIII hubo varios colectores esporádicos en Sierra Morena, pero solo hubo uno que enviara sistemáticamente al Real Gabinete muestras de botánica, el cura párroco de la villa de Montoro, Fernando López de Cárdenas (1719-1786) (Montero y Devesa 2020). Era colector del Real Gabinete, no del Jardín Botánico, por lo que todos sus envíos los hace a la primera Institución, ya fueran plantas o ya fueran rocas y fósiles, que envió gran cantidad.

El que llegó a ser conocido como "el cura de Montoro", Fernando José del Carmen López de Cárdenas, nació en Priego de Córdoba y murió en Montoro, a los 67 años de edad (Ramírez de las Casas Deza, MSS. s/f; Lucena Llamas 2001, 1995).

Aunque no era un erudito, poseía cultura y fue, sin duda, uno de los colectores más prolíficos en la Península que tuvo el Real Gabinete en ese último tercio del siglo XVIII (Barras de Aragón 1920; Montero 2003; Montero y Devesa 2020). Entre 1776 y 1785 los envíos eran continuos, tanto de fósiles y rocas, como de maderas y semillas, restos arqueológicos, tierras, y algunos animales. Sus conocimientos en historia natural, en general, eran escasos, por lo que cuando recogía ejemplares botánicos se solía hacer acompañar en sus colectas por el farmacéutico de Montoro, Manuel de la Vega (Martínez y Reguera 1916).

Cuando hacía envíos de lotes de ejemplares, siempre mandaba con pocos días de intervalo una carta con un inventario sucinto y, por separado, un documento extenso con una explicación detallada de cada ítem. Los largos escritos que acompañan a los envíos de López de Cárdenas son en parte descriptivos y en parte bibliográficos. Es decir, describe la especie sucin- 


\begin{tabular}{|c|c|c|c|c|c|c|c|}
\hline Oct $/ 1778^{1}$ & Marzo $1779^{2}$ & Jun $/ 1779^{3}$ & Dic/17794 & Oct $/ 1780^{5}$ & Jun/1781 ${ }^{6}$ & Dic $/ 1782^{7}$ & Marzo $1784^{8}$ \\
\hline \multirow[t]{17}{*}{ Terebinto (14 ej.) } & Terebinto & Tamujo & Roble & Sabina & Mostajo & Durazno & Romero blanco \\
\hline & Enebro & Espino prieto & Brezo & Texo & $\begin{array}{l}\text { Árbol silvestre de } \\
\text { hojas de parra }\end{array}$ & Vid ô parra & Olmo \\
\hline & $\begin{array}{l}\text { Alcornoque } \\
\text { casquero }\end{array}$ & Tamarisco ô taray & Mirto ô arrayhan & Box Aelo & Lavirnago & Oliva & Chopo \\
\hline & $\begin{array}{l}\text { Alcornoque } \\
\text { segundero }\end{array}$ & Philyrea o durillo & Brusco & $\begin{array}{l}\text { Sanguino } \\
\text { Acer }\end{array}$ & Hiniesta & Romero & Barba hija \\
\hline & Quejigo & Jara & Laurel & Retama & Avellano & Tartago & Mundo \\
\hline & Encina & Aliso & $\begin{array}{l}\text { Hediondo o } \\
\text { apocino }\end{array}$ & Giniesta & Castaño & Espino prieto & $\begin{array}{l}\text { Charnaca ô } \\
\text { manzanillo }\end{array}$ \\
\hline & Coscoja & Almezo & Yedra & Gayomba & Cinamomo & Cerezo & Mespilo \\
\hline & Mesto & Adelfa & Azofaifo & Coeso & $\begin{array}{l}\text { Higuera chumba o } \\
\text { de infierno }\end{array}$ & Albaricoque & Limón \\
\hline & $\begin{array}{l}\text { Agnocasto ô } \\
\text { sauzgatillo }\end{array}$ & & Algarrobo & Rascaviejas & Cabrahigo & Palma y su elatta & Naranjo \\
\hline & & & Chilladera & & Serbal & Guindo & Lentisco común \\
\hline & & & Sarguilla & & Nispolo & Tila o tilon & $\begin{array}{l}\text { Cambrón ô } \\
\text { rhamno }\end{array}$ \\
\hline & & & Sauze & & $\begin{array}{l}\text { Garrullo o } \\
\text { piruetano }\end{array}$ & Raíz de retama & \\
\hline & & & Fresno & & Pita & Gayomba silvestre & \\
\hline & & & Madroño & & Cipres & Almendro & \\
\hline & & & Agno Casto & & $\begin{array}{l}\text { Pilosella de } \\
\text { Dioscorides o } \\
\text { yerba candilexa }\end{array}$ & Granado & \\
\hline & & & & & & $\begin{array}{l}\text { Eliotropo o girasol } \\
\text { maior }\end{array}$ & \\
\hline & & & & & & Toba & \\
\hline
\end{tabular}

tamente, con poco interés botánico dados sus escasos conocimientos y le añade notas de algunos autores clásicos, normalmente sobre usos médicos, agrícolas o de otro tipo (Montero y Devesa 2020).

Las colectas botánicas de López de Cárdenas comienzan en el año de 1777, recogiendo lino, cornicabra y enebro (MSS/2541. BDH). Y lo recoge en Sierra Morena, lo que puede querer decir, exclusivamente, que las colectas las hace en las "8 leguas de termino, que tiene esta villa en la Sierra Morena" (Calatayud Arinero 1987, ref. 649). Un año después realiza su primer envío de maderas, en concreto, de cornicabra (Pistacia terebinthus L.).

Entre 1779 y 1784 realiza bastantes envíos de maderas (tabla 1) y semillas $\mathrm{y}$, en mucha menor medida, de frutos, agallas y otros, pero no se conoce con exactitud cuántos envíos o qué cantidad de ítems envía, dada la pérdida de documentación de archivo. Por ejemplo, en los años 1780 y 1781 hubo al menos un envío por año de los que no hay actualmente referencia documental de archivo, salvo una anotación en un documento de otro envío que habla de la pérdida de un ítem de ciprés en un envío anterior (Calatayud Arinero 1987, ref. 649). Sin embargo, Barras de Aragón hace constar dos listados de
Tabla 1. Maderas de árboles y arbustos que envió José López de Cárdenas al Real Gabinete desde 1778 hasta 1784 de las que queda constancia documental. Donde no aparece cantidad se entiende que es un ejemplar

${ }^{1}$ Calatayud Arinero 1987: 536; ${ }^{2}$ Calatayud Arinero 1987: 549; ${ }^{3}$ Calatayud Arinero 1987: 566; ${ }^{4}$ Calatayud Arinero 1987: 587; ${ }^{5}$ Barras de Aragón 1920; ${ }^{6}$ Barras de Aragón 1920; ${ }^{7}$ Calatayud Arinero 1987: 690; ${ }^{8}$ Calatayud Arinero 1987: 764 
esos años (Barras de Aragón 1920), lo que quiere decir que esa documentación de archivo con los listados se ha perdido entre 1920 y 2020.

\section{¿Qué quedaba en el siglo XIX de aquellos envíos a la corte?}

En 1819, en el Real Gabinete, se realizó un inventario de las maderas que había en la Sala del Vegetal (tabla 2), apareciendo ochenta y tres ítems de Sierra Morena (ACN0125/101. AMNCN). Estos ejemplares, que se habían enviado desde Córdoba, permanecieron en el Real Gabinete hasta 1844, año en que la Junta Gubernativa del Museo de Ciencias Naturales decide enviar todas las colecciones botánicas del Real Gabinete al Real Jardín Botánico. Se trataba de miles de piezas, de maderas, raíces, semillas, frutos, pliegos de herbario, e incluso algún material etnológico, dispuestas en veintinueve grandes cajones que contenían cada uno desde algo más de un centenar de piezas a varios centenares, en gran parte de América, pero también de Asia, de España y muchas sin localidad de origen (ACN1058/002. AMNCN).

En ese inventario de traspaso hay ochenta y cuatro ejemplares que tienen como procedencia Sierra Morena (tabla 3). La gran mayoría consiste en medio tronco de una cuarta de largo o de alto y entre dos y nueve dedos de diámetro. Las especies son las mismas que aparecen en el inventario de 1819 (tabla 2), pero con algunas disonancias: en la lista de 1819 aparece lampazo ô bardana (sic), y en la de 1844 no, y en esta última aparecen brusco, castano, azebo, sauze, palma y su elata y agno-casto (sic) y en la anterior no.

\section{Ejemplares de la colección actual del Herbario MA del Real Jardín Botánico de Madrid}

En una primera búsqueda en el Herbario, dentro de los fondos antiguos sin catalogar, aparecieron cincuenta y siete ejemplares (MA-01-00940682 a MA-01-00940700). Posteriormente se encontraron otros diecisiete ejemplares (MA-01-00948232 a MA-01-00948248) (tabla 4).

Como puede observarse en las imágenes de la página 9, todos estaban cortados hasta la mitad de su longitud dejando la otra mitad en su estado original (superior). Las zonas cortadas están pulidas, un trabajo hecho en el Real Gabinete, como deja claro su director en una anotación marginal en un documento de envío (Calatayud Arinero 1987, ref. 690). Sin embargo, existen bastantes ejemplares a los que se les ha arrancado la mitad sin cortar, dejando la mitad del tronco en toda la sección longitudinal (inferior). Este curioso expolio fue realizado por las tropas francesas durante la ocupación de Madrid para llevarse una muestra de cada especie de madera a su país (ACN0125/101. AMNCN). 


\begin{tabular}{|lll|}
\hline Taray & Mesto & Madre Selva \\
\hline Almezo & Durillo, ô Filirea & Sanguino \\
\hline Chilladera & Eliotropo & Espino blanco \\
\hline Alcornoque de corcho nuevo & Fresno & Aliso \\
\hline Alcornoque de corcho viejo & Ciruelo & Retama \\
\hline Higuera ô Cabrahigo & Zumaque & Caña ferula \\
\hline Olivo & Laurel & Parra, ô Vid \\
\hline Raiz de retama & Algarrobo & Peral \\
\hline Almendro & Coeso & Terevinto \\
\hline Tartago & Cinamomo & Azar \\
\hline Arrayan & Madroño & Romero. 2 exempes \\
\hline Guindo & Ciprès & Serbal \\
\hline Quexigo & Coscoja & Azofaifo \\
\hline Toxo, 3 exemplares & Pero & Lampazo, ô Bardana \\
\hline Granado & Nispolo & Adelfa \\
\hline Box & Brezo & Hediondo \\
\hline Cerezo & Gayamba. 2 exempes & Zarza \\
\hline Acebo & Retama & Xara \\
\hline Encina & Rasca viejas & Membrillo \\
\hline Enebro, ô Alerce & Carullo, ô Piruetano & Hiedra \\
\hline Avellano & Mostajo & Pita \\
\hline Sabina & Alvaricoque & Chilladera, ô Labiernago \\
\hline Espino Prieto, 2 exempes & Agnocasto. 2 exempes & Espino Prieto \\
\hline Hiniesta macho & Tova & Tamujo ô Licio \\
\hline Hiniesta hembra & Durazno & Tila \\
\hline & Roble & Balaustias \\
\hline
\end{tabular}

\begin{tabular}{|c|c|c|}
\hline Brusco & Guindo & Gaiomba \\
\hline Azar & Madroño & Texo \\
\hline Almendro & Agno-casto & Fresno \\
\hline Terevinto & Peral & Pita \\
\hline Coeso & Enebro ó alerce & Ciruelo \\
\hline Caña - Kerula & Almezo & Xara \\
\hline Hiedra & Alcornoque de corcho & Cinamomo \\
\hline Hediondo & Brezo & Espino-prieto \\
\hline Durazno & Serbal & Algarrobo \\
\hline Coscoja & Laurel & Chilladera ó Labiernago \\
\hline Hiniesta macho & Alcornoque de corcho nuevo & Tila \\
\hline Balaustia & Taray & Mostajo \\
\hline Garullo ó Piruetano & Encina & Retama \\
\hline Cerezo & Box & Espino prieto \\
\hline Raiz de Retama & Olivo & Nispolo \\
\hline Qexigo & Arrayan & Romero \\
\hline Castano & Sauze & Zarza \\
\hline Sabina & Espino Prieto & Retama \\
\hline Higuera ó Cabrahigo & Rascaviejas & Zumaque \\
\hline Avellano & Palma y su elata & Roble \\
\hline Mesto & Hiniesta & Ciprés \\
\hline Azebo & Adelfa & Espino blanco \\
\hline Albaricoque & Pero & Tamujo ó licio \\
\hline Chilladera & Agno-casto & Durillo ó Filirea \\
\hline Azofaifo & Sanguino & Gayamba \\
\hline Romero & Membrillo & Madreselva \\
\hline Tova & Granado & Aliso \\
\hline Tartágo & Parra ó vid & Heliotropio \\
\hline
\end{tabular}

Tabla 2. Listado de los ochenta y tres ejemplares de Sierra Morena que figuran en el inventario de maderas que se encontraban en la Sala del Vegetal del Real Gabinete de Historia Natural en 1819. Se ha puesto la grafía del documento original. No hay localidades de colecta

Tabla 3. Listado parcial de maderas del "Inventario de maderas, resinas y frutos que de orden de la Junta Gubernativa del museo de ciencias naturales, su fecha 11 de junio de 1844 deben trasladarse al Jardin Botanico de esta Corte desde el Gabinete de Historia natural, donde en la actualidad se hallan" (11 de junio de1844. Documento ACN1058/002. AMNCN). Consta de ochenta y cuatro ejemplares y solo se citan los que tienen como procedencia Sierra Morena. Nunca aparecen localidades concretas de colecta. Se ha puesto la grafía del documento original. Son setenta y nueve ítems 
Superior izquierda, vista longitudinal del ejemplar MA-01-00940661, higuera ò cabrahigo (posible Ficus carica L.). No se ha encontrado la fecha de envío al Real Gabinete de Historia Natural

Superior derecha, vista longitudinal del ejemplar MA-01-00940668, tartago (posible Euphorbia lathyris L.), enviada al Real Gabinete en noviembre de 1782

Inferior izquierda, vista longitudinal del ejemplar MA 01-00940655, ciruelo (posible Prunus domestica L.), enviado al Real Gabinete de Historia Natural en junio de 1781

Inferior derecha, vista longitudinal del ejemplar MA01-00940650, gaiomba (posible Spartium junceum L.), enviado al real Gabinete de Historia Natural en noviembre de 1782 | fotos Ángel Montero, autor de todas las imágenes del artículo
Tabla 4 (pp. 127-128). Listado, con números del inventario general del Herbario del Real Jardín Botánico de Madrid (MA) y del inventario de la colección complementaria (GHN), que hace referencia al Gabinete de Historia Natural. Consta de setenta y cuatro ejemplares de maderas de Sierra Morena que se conservan actualmente en dicho Herbario MA. Se ha puesto la grafía original de los nombres manuscritos y/o de las etiquetas
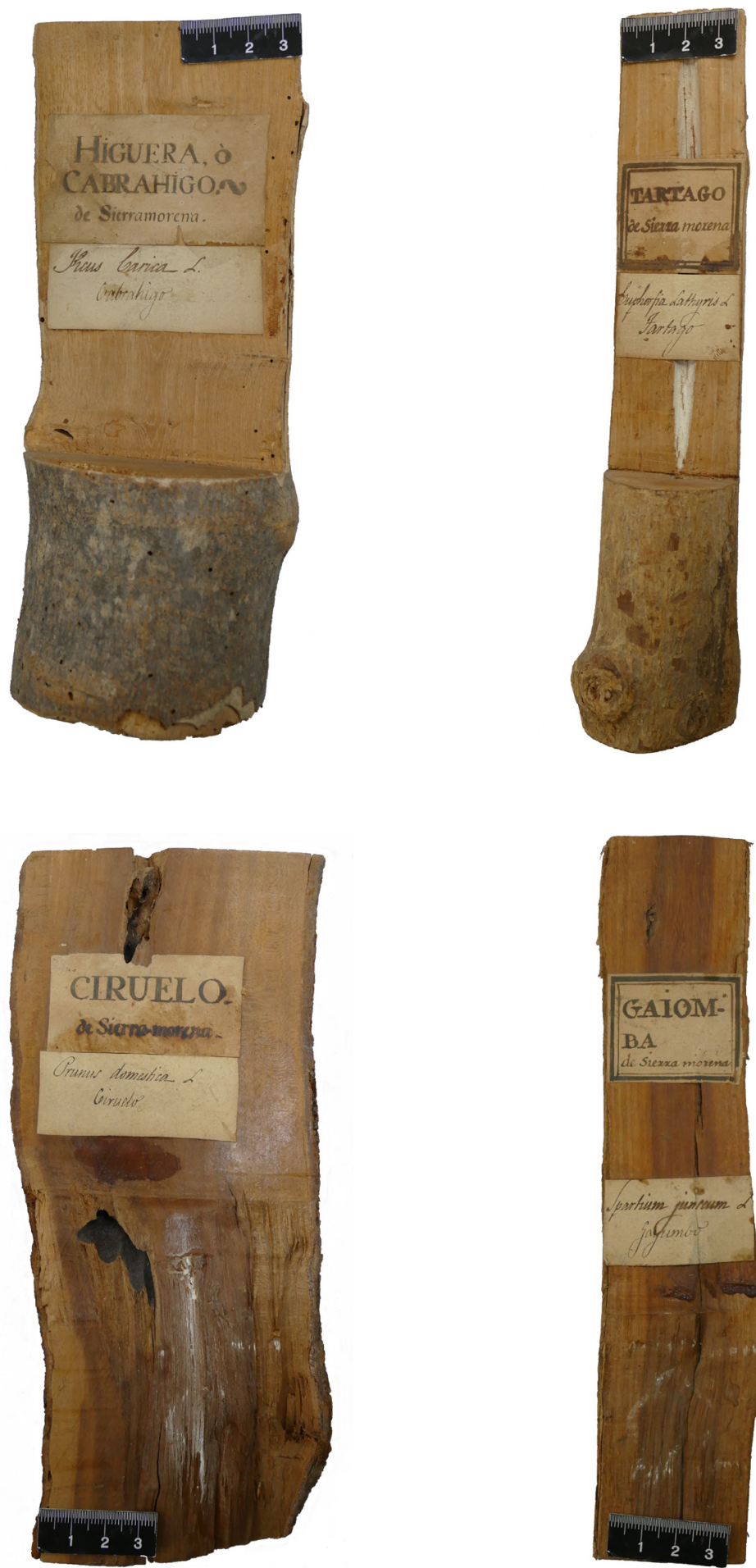


\begin{tabular}{|c|c|c|}
\hline MA-01-00940682; MA-01-00948232 & GHN_0040; GHN_0059 & Chilladera (2 ejemplares) \\
\hline MA-01-00940665 & GHN_0023 & Alcornoque \\
\hline MA-01-00940661 & GHN_0019 & Higuera ô Cabrahigo \\
\hline MA-01-00940675 & GHN_0033 & Olivo \\
\hline MA-01-00940645 & GHN_0003 & Raiz de retama \\
\hline MA-01-00940698 & GHN_0056 & Almendro \\
\hline MA-01-00940668 & GHN_0026 & Tartago \\
\hline MA-01-00940658 & GHN_0016 & Arrayan \\
\hline MA-01-00940652 & GHN_0010 & Texo \\
\hline MA-01-00940696 & GHN_0054 & Box \\
\hline MA-01-00940693 & GHN_0051 & Cerezo \\
\hline MA-01-00940674 & GHN_0032 & Encina \\
\hline MA-01-00940690 & GHN_0048 & Enebro o Alerce \\
\hline MA-01-940686 & GHN_0044 & Sabina \\
\hline MA-01-00940644; MA-01-00940646 & GHN_0002; GHN_0004 & Espino Prieto (2 ejemplares) \\
\hline MA-01-00940666 & GHN_0024 & Hiniesta \\
\hline MA-01-00940691 & GHN_0049 & Fresno \\
\hline MA-01-00940655 & GHN_0013 & Ziruelo o Ciruelo \\
\hline MA-01-00940683 & GHN_0041 & Zumaque \\
\hline MA-01-00940685 & GHN_0043 & Algarrobo \\
\hline MA-01-00940688 & GHN_0046 & Coeso \\
\hline MA-01-00940699 & GHN_0057 & Cinamomo \\
\hline MA-01-00940692 & GHN_0050 & Madroño \\
\hline MA-01-00940660 & GHN_0018 & Ciprès \\
\hline MA-01-00940679 & GHN_0037 & Coscoja \\
\hline MA-01-00940657 & GHN_0015 & Nispolo \\
\hline MA-01-00940676 & GHN_0034 & Brezo \\
\hline MA-01-00940650; MA-01-00940670 & GHN_0008; GHN_0028 & Gaiomba o Gayamba (2 ejemp.) \\
\hline MA-01-00940681; MA-01-00940694 & GHN_0039; GHN_0052 & Retama (2 ejemplares) \\
\hline MA-01-00940700 & GHN_0058 & Rascaviejas \\
\hline MA-01-00940672 & GHN_0030 & Albaricoque o Alvaricoque \\
\hline MA-01-00940678; MA-01-00948236 & GHN_0036; GHN_0063 & Agnocasto (2 ejemplares) \\
\hline MA-01-00940654 & GHN_0012 & Roble \\
\hline MA-01-00940662 & GHN_0020 & Madreselva \\
\hline MA-01-00940671 & GHN_0029 & Sanguino \\
\hline MA-01-00940695 & GHN_0053 & Espino blanco \\
\hline MA-01-00940663 & GHN_0021 & Caña-Ferula \\
\hline MA-01-00940669 & GHN_0027 & Parra o Vid \\
\hline MA-01-00940647; MA-01-00940648 & GHN_0005; GHN_0006 & Romero (2 ejemplares) \\
\hline MA-01-00940677 & GHN_0035 & Azofaifo \\
\hline MA-01-00940697 & GHN_0055 & Adelfa \\
\hline MA-01-00940680 & GHN_0038 & Hediondo \\
\hline MA-01-00940664 & GHN_0022 & Zarza \\
\hline MA-01-00940689 & GHN_0047 & Xara \\
\hline MA-01-00940673 & GHN_0031 & Membrillo \\
\hline MA-01-00940684 & GHN_0042 & Tamujo o Licio \\
\hline MA-01-00940687 & GHN_0045 & Tila \\
\hline MA-01-00940656 & GHN_0014 & Sauze \\
\hline MA-01-00940649 & GHN_0007 & Balaustia o Granado silbestre \\
\hline MA-01-00948233 & GHN_0060 & Granado \\
\hline MA-01-00948234 & GHN_0061 & Mesto \\
\hline MA-01-00948235 & GHN_0062 & Azar \\
\hline MA-01-00948237 & GHN_0064 & Avellano \\
\hline
\end{tabular}




\begin{tabular}{cll} 
MA-01-00948238 & GHN_0065 & Durazno \\
MA-01-00948239 & GHN_0066 & Quexigo \\
MA-01-00948240 & GHN_0067 & Durillo o Filirea \\
MA-01-00948241 & GHN_0068 & Azebo \\
\hline MA-01-00948242 & GHN_0069 & Pero \\
MA-01-00948243 & GHN_0070 & Serbal \\
MA-01-00948244 & GHN_0071 & Castaño \\
MA-01-00948245 & GHN_0072 & Aliso \\
\hline MA-01-00948246 & GHN_0073 & Pita \\
\hline MA-01-00948247 & GHN_0074 & Alcornoque de Corcho nuevo \\
\hline MA-01-00948248 & GHN_0075 & Almezo \\
\hline
\end{tabular}

Casi todos los ejemplares de maderas de la colección del Herbario MA del Jardín Botánico tienen textos manuscritos por López de Cárdenas sobre las partes cortadas transversalmente, y excepcionalmente sobre la corteza (véase imágenes de la página siguiente). También presentan todos ellos dos etiquetas pegadas sobre la parte cortada longitudinalmente. Una de las etiquetas repite el texto manuscrito de López de Cárdenas con denominaciones populares: ciruelo, higuera, etc. y pertenece con toda seguridad al Real Gabinete (s. XVIII), ya que el estilo de letra es el mismo al de la etiqueta que conserva un cristal de yeso de Aguilar de la Frontera (Córdoba), en la que pone que el ítem fue enviado por el cura de Montoro. Es el único ejemplar de rocas, enviado por López de Cárdenas al Real Gabinete, que sobrevive en las colecciones del actual Museo Nacional de Ciencias Naturales-CSIC. La otra etiqueta (con la especie, según Linneo), se puso probablemente ya a mitad del siglo XIX en el Real Jardín Botánico, seguramente bajo la supervisión del que había sido nombrado en 1837 Jefe Local del Real Jardín y fue último receptor de aquellos envíos, José Demetrio Rodríguez (1780-1846), ya que las determinaciones botánicas son modernas: Prunus, Ficus, etc.

\section{CONCLUSIONES}

La documentación de colecciones históricas de museos de Ciencias Naturales ha sido siempre una labor difícil y, en muchos casos, desagradecida. A la falta de información, que ya tuvieran los ejemplares en origen, se suma la que se ha extraviado a lo largo del tiempo. Es normal que las piezas de gabinetes de Historia Natural y primeros museos tengan una información muy deficiente dado que los colectores no solían tener formación naturalista y ese atesoramiento de piezas solía tener como única finalidad la contemplación o el asombro, no el estudio.

Por eso, el encontrar documentación que atestigüe tanto la trayectoria del ejemplar o colección, como su origen y el por qué de su colecta es fundamental en museos con colecciones históricas, ya que le da a las piezas un valor como mínimo histórico, y a veces múltiple. 


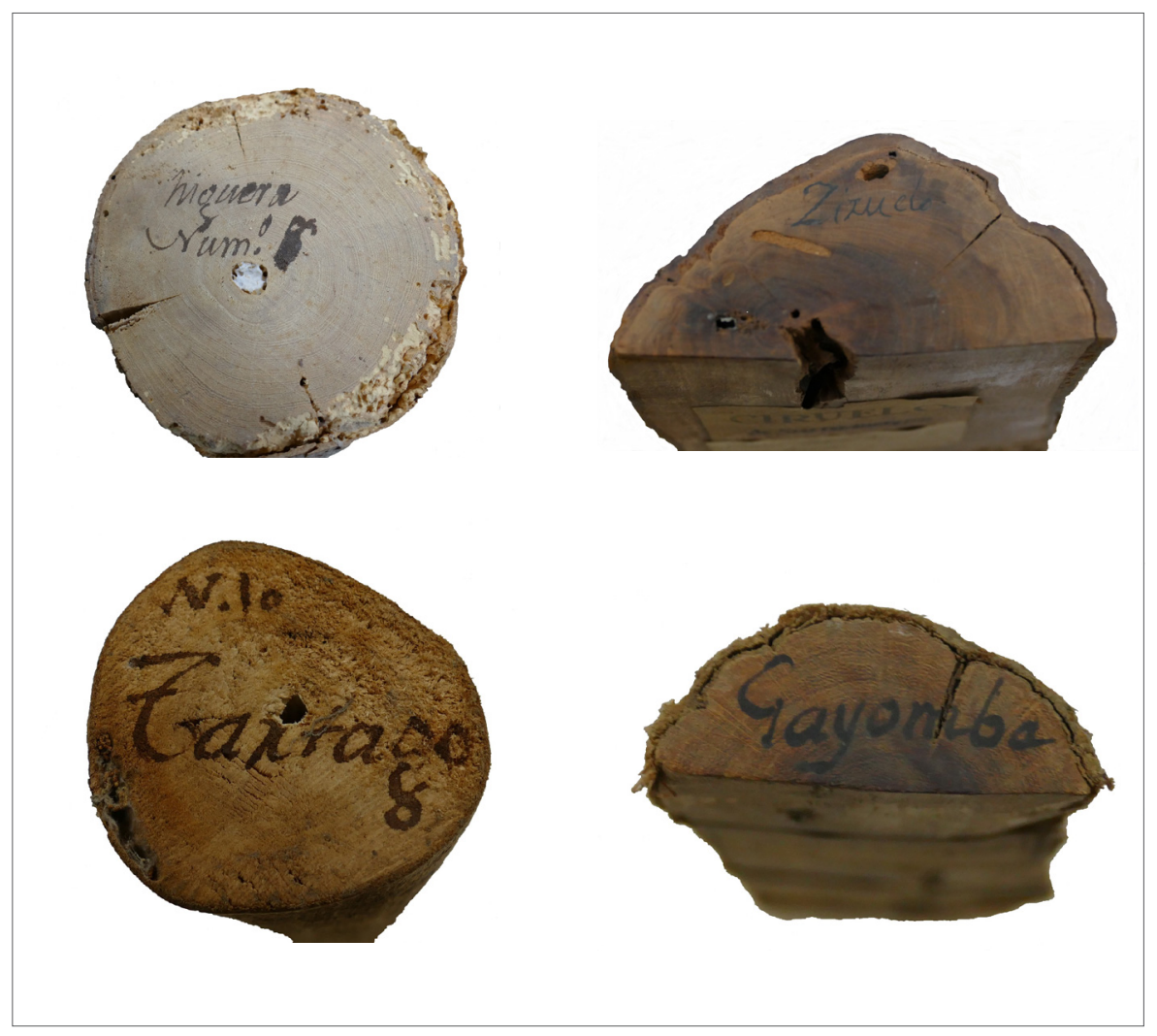

Siguiendo con lo dicho anteriormente y en el caso de la colección de maderas estudiada se ha podido utilizar: a) la documentación enviada en el siglo XVIII, por López de Cárdenas al Real Gabinete de Historia Natural, informando de los ejemplares que enviaba a la corte, b) el inventario de las colecciones que el Real Gabinete hizo después de la ocupación francesa y el de la cesión al Real Jardín Botánico a mediados del siglo XIX, y c) los textos manuscritos sobre el ejemplar y las etiquetas adheridas a las piezas encontradas en el Herbario MA del Real Jardín Botánico de Madrid. Después del estudio de todo lo dicho, se puede afirmar que la colección de maderas de Sierra Morena que conserva dicho Herbario son los restos de diferentes envíos de Fernando López de Cárdenas desde Montoro (Córdoba) al Real Gabinete de Historia Natural impulsado por la Instrucción de colecta que se emitió desde la Corte en 1776.

De aquellas colectas de semillas, frutos y maderas realizadas por el autor entre 1777 y 1784 y enviadas al Real Gabinete solo han perdurado las maderas cortadas.

Al no disponer de toda la documentación sobre aquellas colectas no se puede saber el total de especies, ni la cantidad global de ejemplares o ítems
De izquierda a derecha, de arriba abajo:

Vista transversal del ejemplar MA-01-00940661, higuera ò cabrahigo

Vista transversal del ejemplar MA-01-00940655, ziruelo o ciruelo

Vista transversal del ejemplar MA-01-00940668, tartago

Vista transversal del ejemplar MA-01-00940650, gaiomba 
Vista longitudinal externa (corteza) del ejemplar MA01-00940668, tartago

\section{Agradecimientos}

A Esther García, Jefa de la Unidad de Archivo y Biblioteca del Real Jardín Botánico de Madrid-CSIC, quien me confirmó la existencia de ejemplares botánicos originarios del Real Gabinete de Historia Natural en esa institución; a Leopoldo Medina, Jefe de la Unidad Técnica de Herbario MA del Real Jardín Botánico de Madrid-CSIC y a Luis Alté, su ayuda en mis estancias y consulta del material de Sierra Morena allí almacenado. Y, por último, a Mónica Vergés, Responsable del archivo del Museo Nacional de Ciencias Naturales y a los ayudantes Pilar Rodríguez y Manuel Parejo, por facilitarme documentos de esta institución.

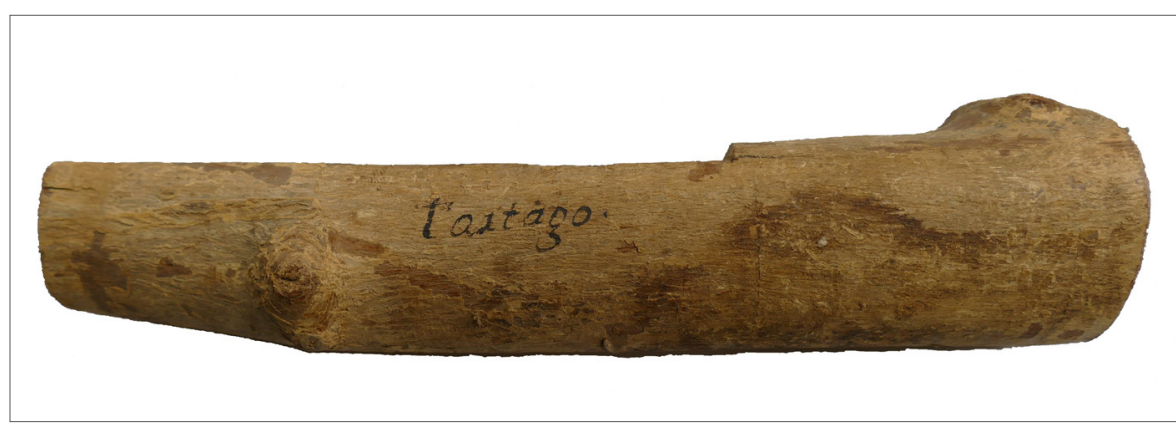

enviados, y, lógicamente, tampoco qué cantidad total de ejemplares se han extraviado en estos dos siglos y medio. Por ejemplo, sabemos que López de Cárdenas hizo en 1782 tres envíos de botánica (Barras de Aragón 1920) y solo tenemos documentado uno. Y tampoco tenemos documentado ningún envío en 1783 y es extraño que no hiciera al menos uno.

En otro sentido, llama la atención la inexistencia en la colección actual de alguna muestra de terebinto, dado que en total se mandaron quince ítems de esta especie y aparecen en todos los inventarios. Probablemente todas las bajas, tanto en el Real Gabinete como en el Real Jardín, lo fueron por su mal estado de conservación. A pesar de todos los posibles avatares, las cantidades de ejemplares de cada etapa son semejantes: El resultado de la tabla 1 arroja ochenta y cuatro ejemplares más quince terebintos, el de la tabla 2 ochenta y tres ejemplares en total y el de la tabla 3 vuelve a los ochenta y cuatro ejemplares. Solo la cantidad de la tabla 4 baja un poco, a setenta y cuatro ejemplares.

El haber situado el origen y la trayectoria histórica de esta colección de maderas de Sierra Morena abre el camino para documentar el resto de la colección de maderas cortadas de otras localidades y colectores, enviadas al Real Gabinete en el último tercio del siglo XVIII y primero del XIX. Estas, permanecen almacenadas en el Herbario MA del Real Jardín Botánico CSIC como resultado de aquel traspaso de ejemplares botánicos desde el Real Gabinete de Historia Natural en 1844. 


\section{BIBLIOGRAFÍA}

- Lemoine Villicaña, E. (1961) Instrucción para aumentar las colecciones del Gabinete de Historia Natural de Madrid - 1776 [ed. facsímil de la anónima Instrucción hecha de orden del Rei N.S. para que los Virreyes, Gobernadores, Corregidores, Alcaldes mayores é Intendentes de Provincias en todos los dominios de S. M. puedan hacer escoger, preparar y enviar á Madrid todas las producciones curiosas de Naturaleza que se encontraran en las Tierras y Pueblos de sus distritos, á fin de que se coloquen en el Real Gabinete de Historia Natural que S. M. ha establecido en esta Corte para beneficio é instrucción pública]. Boletín del Archivo General de la Nación, 2(2.2), pp. 189-230 Disponible en: https://bagn.archivos.gob.mx/index.php/legajos/article/ view/1636 [Consulta: 11/01/2022]

- Añón, C. (1987) Real Jardín Botánico de Madrid. Sus Orígenes: 1755-1781. Madrid: Real Jardín Botánico-CSIC

- Armada, J. (2005) Las colecciones de plantas vivas del Real Jardín Botánico. En: El Real Jardín Botánico de Madrid (1755-2005): ciencia, colección y escuela. Barcelona; Madrid: Lunwerg, pp. 114-132

- Barras de Aragón, F. (1920) La labor de D. Fernando López de Cárdenas, cura de Montoro, como naturalista. Boletín de la Real Academia Sevillana de Buenas Letras, n. ${ }^{\circ} 16$, pp. $149-159$

- Barreiro, A.J. (1992) El Museo Nacional de Ciencias Naturales (1771-1935). Madrid: Doce Calles

- Barreiro, A.J. (1944) El Museo Nacional de Ciencias Naturales. Madrid: Consejo Superior de Investigaciones Científicas

- Calatayud Arinero, M. ${ }^{\mathrm{a}}$ Á. (1987) Catálogo de documentos del Real Gabinete de Historia Natural (17521786): fondos del Archivo del Museo Nacional de Ciencias Naturales. Madrid: Consejo Superior de Investigaciones Científicas

- Calatayud Arinero, M. ${ }^{a}$ A. (1986) Antecedentes y creación del Real Gabinete de Historia Natural de Madrid. Arbor, n. ${ }^{\circ} 123$, pp. 9-31

- Calatayud Arinero, M. ${ }^{a}$ Á. (1988) Pedro Franco Dávila: primer director del Real Gabinete de Historia Natural fundado por Carlos III. Madrid: Museo Nacional de Ciencias Naturales

- Gómez Ortega, C. (1993) Instrucción sobre el modo más seguro y económico de transportar plantas vivas. $1 .^{\text {a }}$ ed. 1779. Madrid: Fundación de Ciencias de la Salud; Sevilla: Sociedad Estatal Quinto Centenario. Reprod. facs. de la ed. de: Madrid: por D. Joachin Ibarra..., 1729

- Hernández-Pacheco, E. (1944) El Museo de Ciencias Naturales y sus naturalistas en los siglos XVIII y XIX. En: EI Museo Nacional de Ciencias Naturales. Madrid: s.n., 1944 (Toledo: Tall. Graf. de Rafael G.-Menor), pp. 5-81
- López, G. (2005) Desde la creación del Jardín de Migas Calientes (1755) hasta A.J. Cavanilles (1801-1804). En: El Real Jardín Botánico de Madrid (1755-2005). Barcelona; Madrid: Lunwerg, pp. 15-27

- Lucena Llamas, J. (2001) López de Cárdenas: Un prieguense ilustrado afincado en Montoro, autor de dos libros sobre Espejo. En: Crónica de Córdoba y sus Pueblos. Córdoba: Asociación Provincial Cordobesa de Cronistas Oficiales, VII, pp. 57-80

- Lucena Llamas, J. (1995) Escritores montoreños. Córdoba: Diputación Provincial de Córdoba, Área de Cultura; Montoro: Ayuntamiento de Montoro

- Martínez y Reguera, L. (1916) Reseña HistóricaDescriptiva de la noble, leal y patriótica Ciudad de Montoro. Andújar: Imprenta La Puritana

- Montero, A. (2003) La Paleontología y sus colecciones desde el Real Gabinete de Historia Natural al Museo Nacional de Ciencias Naturales. Madrid: Consejo Superior de Investigaciones Científicas (Monografías/Museo Nacional de Ciencias Naturales; 19)

- Montero, A. y Devesa, J.A. (2020) Los conocimientos botánicos de Fernando López de Cárdenas, colector del Real Gabinete de Historia Natural en Córdoba (España) en el siglo XVIII. Acta Botánica Malacitana, vol. 45. Disponible en: https://doi.org/10.24310/Actabotanicaabmabm.v45i.9619 [Consulta: 12/01/2021]

- Puerto Sarmiento, F. J. (1988) La ilusión quebrada. Botánica, sanidad y política científica en la España ilustrada. Barcelona: Serbal; Madrid: CSIC

- Ramírez de las Casas Deza, L. M. ${ }^{a}$. Libro de razón de la genealogía, derechos y pertenencias, honores, empleos y escritos de Don Fernando Joseph Lopez de Cardenas. En: Biografía de cordobeses ilustres (obra inédita). Biblioteca Provincial de Córdoba, sección manuscritos. Parte 2. ${ }^{\text {a }}$, legajos L-R

- Velayos, G., García, E. y Velayos, M. (2020) About the location of the gardens cultivated by Joseph Quer in Madrid and, especially, the Botanical Garden of Migas Calientes. Anales del Jardín Botánico de Madrid, vol. 77 (1). Disponible en: https://rjb.revistas.csic.es/index.php/rjb/article/view/505 [Consulta: 12/01/2022] 